\title{
A Note on Goal Programming Approach to Tea Industry of Barak Valley of Assam
}

\author{
Nabendu Sen \\ Department of Mathematics, Assam University , Pin-788011, Silchar, India
}

\begin{abstract}
Application of Goal Programming in industry is an important tool to planners. A Goal programming model regarding tea production in Barak Valley[7] and its extension developed here have been presented. The proposed models yield optimal solutions. It is very easy to understand which can serve managers by providing optimal solution to different goals involving production, profit, demand etc. With the help of numerical example, the proposed models have been validated. Finally analyses of the results obtained have been carried out. It is found that total production goal can be achieved along with other goals in both the models. The two models are compared and the former is found to be more efficient than latter.
\end{abstract}

\section{Keywords Goal Programming, Management, Production, Optimization}

\section{Introduction}

Planning and production are known to be responsible for the development of an industry. Barak valley of Assam (India) is full of green tea gardens and some of them are producing made tea fromgreen leafs. The management of tea industries of similar nature is having different objectives to attain them within specified period of time. In this section some literatures on Goal programming and its application have been presented before the analys is of the models.

Goal programming and its applications in diverse field have been studied by different authors. Cobb and Warner[1],Trivedi[2] used Goal programming model to allocate resources in management related problems of quality service. $\mathrm{Nja}$ and Udafia[3] applied Goal programming to flour producing companies. Vivekanandan etl[4] developed Goal Programming model for the optimization of cropping pattern for a particular region. Shim and Siegel[5] developed Goal programming model with sensitivity analysis to determine the decision variables and goal deviations. Pati etl[6] developed a mixed integer goal programming model for paper recycling system. The goals considered in the model have economical, social as well as quality implications on the paper recycling industry. Further we can find some of the important literature on goal programming in[8-15]. Recently Sinha and Sen[7] developed Goal programming model regarding tea production of different grades in tea industries of Barak

* Corresponding author:

nsen_16@yahoo.co.in (Nabendu Sen)

Published online at http://journal.sapub.org/ajms

Copyright (C) 2012 Scientific \& Academic Publishing. All Rights Reserved
Valley of Assam(India). For best author's knowledge, no empirical study has been carried out so far to measure the effect of reduced cost, dual price on these developed models.

With these above motivations, an effort has been made to study the effect of reduced cost, dual price and change of priorities of goals on these models.

\section{Mathematical Models}

In[7], a Goal Programming model has been formulated keeping in view environ mental conditions of this valley and management point of view. The authors have focused mainly on the production of different grades (according to size) of tea as the main goal and the others goals are set on profit, factory expenditure (production expenditure),demand and over use of different machines assigned for sorting and packing. These goals are given priorities according to their importance. In the extended model of[7], goals on production of different grades of teas are kept in same priority level. Both the models have been given in appendix $\mathrm{A}$ and $\mathrm{B}$ respectively.

\begin{tabular}{|c|c|c|}
\hline Row & Slack or surplus & Dual price \\
\hline 1 & 0.000000 & -1.000000 \\
\hline 2 & 0.000000 & 0.000000 \\
\hline 3 & 120.2170 & 0.000000 \\
\hline 4 & 123.8924 & 0.000000 \\
\hline 5 & 0.000000 & 0.000000 \\
\hline 6 & 0.000000 & 0.000000 \\
\hline 7 & 0.000000 & 0.000000 \\
\hline 8 & 0.000000 & 0.000000 \\
\hline 9 & 0.000000 & 0.000000 \\
\hline 10 & 0.000000 & 0.000000 \\
\hline 11 & 0.000000 & 0.000000 \\
\hline
\end{tabular}




\section{Numerical Illustration}

Now we illustrate these two models with numerical values given in appendix C. LINGO software has been used to solve these models.

The solution of model in appendix A is obtained in 10 iterations which is given below

\begin{tabular}{|c|c|c|}
\hline Variable & Value & Reduced cost \\
\hline$d_{1}^{-}$ & 0.000000 & 1.000000 \\
\hline$d_{2}^{-}$ & 0.000000 & 1.000000 \\
\hline$d_{3}^{+}$ & 0.000000 & 1.000000 \\
\hline$d_{4}^{-}$ & 0.000000 & 1.000000 \\
\hline$d_{5}^{+}$ & 0.000000 & 1.000000 \\
\hline$d_{6}^{+}$ & 0.000000 & 1.000000 \\
\hline$x_{1}$ & 863.5877 & 0.000000 \\
\hline$x_{2}$ & 0.000000 & 0.000000 \\
\hline$x_{3}$ & 21.78273 & 0.000000 \\
\hline$x_{4}$ & 44.99164 & 0.000000 \\
\hline$x_{5}$ & 1237.638 & 0.000000 \\
\hline$d_{1}^{+}$ & 0.000000 & 0.000000 \\
\hline$d_{2}^{+}$ & 0.000000 & 0.000000 \\
\hline$d_{3}^{-}$ & 7899.008 & 0.000000 \\
\hline$d_{4}^{+}$ & 2.386518 & 0.000000 \\
\hline$d_{5}^{-}$ & 20.21698 & 0.000000 \\
\hline$d_{6}^{-}$ & 23.89242 & 0.000000 \\
\hline
\end{tabular}

The solution of model in appendix B is obtained in 17 iterations which is given below

\begin{tabular}{|c|c|c|}
\hline Variable & Value & Reduced cost \\
\hline$d_{1}^{-}$ & 0.000000 & 1.000000 \\
\hline$d_{21}^{-}$ & 0.000000 & 1.000000 \\
\hline$d_{22}^{-}$ & 20.00000 & 0.000000 \\
\hline$d_{23}^{-}$ & 289.7289 & 0.000000 \\
\hline$d_{24}^{-}$ & 0.000000 & .5470690 \\
\hline$d_{25}^{-}$ & 0.000000 & 1.000000 \\
\hline$d_{3}^{-}$ & 0.000000 & .9249073 \\
\hline$d_{4}^{+}$ & 0.000000 & 1.000000 \\
\hline$d_{5}^{-}$ & 1.016861 & 0.000000 \\
\hline$d_{6}^{+}$ & 0.000000 & 1.000000 \\
\hline$d_{7}^{+}$ & 0.000000 & 1.000000 \\
\hline$x_{1}$ & 861.6944 & 0.000000 \\
\hline$x_{2}$ & 0.000000 & $.5919423 \mathrm{E}-01$ \\
\hline$x_{3}$ & .2711217 & 0.000000 \\
\hline$x_{4}$ & 100.0000 & 0.000000 \\
\hline$x_{5}$ & 1207.054 & 0.000000 \\
\hline$d_{1}^{+}$ & 1.019831 & 0.000000 \\
\hline$d_{21}^{+}$ & 361.6944 & 0.000000 \\
\hline$d_{22}^{+}$ & 0.000000 & 1.000000 \\
\hline$d_{23}^{+}$ & 0.000000 & 1.000000 \\
\hline$d_{24}^{+}$ & 0.000000 & .4529310 \\
\hline
\end{tabular}




\begin{tabular}{|c|c|c|}
\hline$d_{25}^{+}$ & 357.0543 & 0.000000 \\
\hline$d_{3}^{+}$ & 0.000000 & $0.7509270 \mathrm{E}-01$ \\
\hline$d_{4}^{-}$ & 7928.646 & 0.000000 \\
\hline$d_{5}^{+}$ & 0.000000 & 1.000000 \\
\hline$d_{6}^{-}$ & 20.41438 & 0.000000 \\
\hline$d_{7}^{-}$ & 23.89167 & 0.000000 \\
\hline
\end{tabular}

\begin{tabular}{|c|c|c|}
\hline Row & Slack or surplus & Dual price \\
\hline 1 & 310.7457 & -1.000000 \\
\hline 2 & 0.000000 & $0.2169800 \mathrm{E}-01$ \\
\hline 3 & 120.4144 & 0.000000 \\
\hline 4 & 123.8917 & 0.000000 \\
\hline 5 & 0.000000 & 0.7160711 \\
\hline 6 & 0.000000 & 0.000000 \\
\hline 7 & 0.000000 & 0.000000 \\
\hline 8 & 0.000000 & -1.000000 \\
\hline 9 & 0.000000 & -1.000000 \\
\hline 10 & 0.000000 & -0.4529310 \\
\hline 11 & 0.000000 & 0.000000 \\
\hline 12 & 0.000000 & $-0.7509270 \mathrm{E}-01$ \\
\hline 13 & 0.000000 & 0.000000 \\
\hline 14 & 0.000000 & -1.000000 \\
\hline 15 & 0.000000 & 0.000000 \\
\hline 16 & 0.000000 & 0.000000 \\
\hline
\end{tabular}

\section{Analysis of the Results}

\subsection{Analysis of Results of First Model}

The production goal and profit goal are fully achieved. The deviational variable $\mathrm{d}_{3}{ }^{-}=7899.008$ means that there is a savings of Rs 7899.008 and the deviational variable $\mathrm{d}_{4}{ }^{+}=$ 2.386518 shows that there is more demand of $2.386518 \mathrm{~kg}$ which can be met with the present production. Our aim is to minimize over use of both the machines but the solution reveals that the machines need not be over used as it is clear from the system constraints on time that the stipulated time is not fully used.

The values of the decision variables indicate that out of five grades, the production of four grades provide optimal solution.

The reduced cost of a variable is the quantity by which the solution deteriorates if we bring that variable in the present solution with same coefficient. So, reduced cost of $x_{2}$ is 0 does not make any change in the solution if we introduce it also.

Dual price mean the quantity by which objective value will improve if we increase the right hand side of constraints by unit quantity. In this solution it is found that there is no dual price associated with any of the constraints.

It has also been observed that on changing priorities between $\left(1^{\text {st }}\right.$ and $\left.2^{\text {nd }}\right),\left(1^{\text {st }}\right.$ and $\left.3^{\text {rd }}\right)$, $\left(1^{\text {st }}\right.$ and $\left.4^{\text {th }}\right),\left(2^{\text {nd }}\right.$ and $\left.3^{\text {rd }}\right)$, $\left(2^{\text {nd }}\right.$ and $\left.4^{\text {th }}\right)$ the present form of this model gives better solution.

\subsection{Analysis of Results of Second Model}

The second model is the extension of first model. The additional goals are set on the production of individual grades of tea. Here total production goal is achieved and moreover the deviational variable $\mathrm{d}_{1}{ }^{+}=1.019831$ means that there is a scope of producing $1.019831 \mathrm{~kg}$ more. The goals on individual production of various grades are not fully achieved in case of $x_{2}$ and $x_{3}$ which are kept in second priority and also the deviational variables $d_{21}^{+}=361.6944$ and $\mathrm{d}_{25}{ }^{+}=357.0543$ show towards more production of the grade $x_{1}$ and $x_{5}$.

The values of decision variables as found, give optimal solution to this extended model. The profit goal is achieved at the expense of individual production goal. One can easily understand about the reduced cost and dual price also. Change of priorities among the goals does not alter the present solution.

\section{Concluding Remarks}

This paper has mainly focused on the use of linear goal programming to make decision makers of tea industry to achieve for production management situation. The models presented in this study involve 10 constraints and 5 decision variables other than deviational variables in first model and 15 constraints in second model with same number of decision variables. On comparison of these two models in this case it is found that first model gives us better objective value than the other. It is to be mention here that the second model is developed by considering the situation where tea industry may have wish to produce different grades of tea due to some compulsion.

The present study not only gives satisfying solution but also provides other relevant information. Management can find in advance what will happen if outcome deviates from objectives. The study of range of coefficients and range of right hand side of constraints will help to understand the scenarios in better way. The present study can further be extended by introducing new constraints, variables and applying fuzzy logic to these models will be of immense help for futher study.

\section{ACKNOWLEDGEMENTS}

Author express sincere thanks to the concern tea industry for providing necessary information. Author also express thanks to Prof.N.K Diwedi ,Banaras Hindu University for encouragement to carry out research in Goal Programming. 


\section{Definitions of symbols}

$X_{i}=$ Quantity of tea of i-th grade.

$\chi=$ Total budget for expenditure for a month.

$\chi_{i}=$ Budget per unit for i-th grade of tea.

$\boldsymbol{t}_{1 i}=$ Time required in machine 1 per unit of $\mathrm{i}$-th grade.

$t_{2 i}=$ Time required in machine 2 per unit of i-th grade.

$\boldsymbol{\beta}_{1}=$ Total allotted time in machine 1 for a month.

$\beta_{2}=$ Total allotted time in machine 2 for a month

$X_{i}=25 x_{i}$.

$A=$ Total allotted space for storage of packed tea.

$A_{i}$ =space required by $X_{i}$.

$\beta_{3}=$ Desired amount of production goal for a month

$\alpha$ =Desired amount of profit for a month.

$\alpha_{i}=$ The profit per unit of i-th grade

$\gamma_{i}=$ The amount to be spent for production per quantity of $\mathrm{i}$-th grade of tea in factory.

$\gamma=$ Desired amount to be spent for production of tea in factory in a month.

$\boldsymbol{\xi}_{i}=l_{i} \%$ of demand of total quantity of $x_{i}$.

$\beta_{4}=$ Total expected demand of all grades of tea to be met in a month.

$\beta_{5}=$ Allowable time for over use of machine 1 in a month.

$\beta_{6}=$ Allowable time for over use of machine 2 in a month.

$\delta_{i}=$ Production target of i-th grade of tea in a month.

$d^{-}=$under-achievement of goals.

$\boldsymbol{d}^{+}=$over-achievement of goals.

$\mathrm{I}=$ The grade of tea depending upon the size $=1,2,3,4,5$.

\section{Appendix A}

\section{Achievement Function:}

Minimize $\mathrm{Z}=P_{1} d_{1}^{-}+P_{2} d_{2}^{-}+P_{3} d_{3}^{+}+P_{4} d_{4}^{-}+$ $P_{5}\left(d_{5}^{+}+d_{6}^{+}\right)$.

Subject to,

System Constraints:

Total budget constraint

$$
\chi_{1} x_{1}+\chi_{2} x_{2}+\chi_{3} x_{3}+\chi_{4} x_{4}+\chi_{5} x_{5} \leq \chi
$$

Allowable time constraints on two machines are

$$
\begin{gathered}
t_{11} x_{1}+t_{12} x_{2}+t_{13} x_{3}+t_{14} x_{4}+t_{15} x_{5} \leq \beta_{1} \\
t_{21} x_{1}+t_{22} x_{2}+t_{23} x_{3}+t_{24} x_{4}+t_{25} x_{5} \leq \beta_{2}
\end{gathered}
$$

Inventory space constraint

$$
A_{1} X_{1}+A_{2} X_{2}+A_{3} X_{3}+A_{4} X_{4}+A_{5} X_{5} \leq A
$$

\section{Goal Constraints:}

\section{Priority P1}

Total Production Goal

$$
x_{1}+x_{2}+x_{3}+x_{4}+x_{5}+d_{1}^{-}-d_{1}^{+}=\beta_{3}
$$

Priority P2

Profit Goal

$$
\alpha_{1} x_{1}+\alpha_{2} x_{2}+\alpha_{3} x_{3}+\alpha_{4} x_{4}+\alpha_{5} x_{5}+d_{2}^{-}-d_{2}^{+}=\alpha
$$

\section{Priority P3}

Production Expenditure Goal

$$
\gamma_{1} x_{1}+\gamma_{2} x_{2}+\gamma_{3} x_{3}+\gamma_{4} x_{4}+\gamma_{5} x_{5}+d_{3}^{-}-d_{3}^{+}=\gamma
$$

\section{Priority $\mathbf{P 4}$}

Goal on Total Demand

$$
\xi_{1}+\xi_{2}+\xi_{3}+\xi_{4}+\xi_{5}+d_{4}^{-}-d_{4}^{+}=\beta_{4}
$$

Priority P5

Goal on Over Use of Machines

$$
\begin{gathered}
t_{11} x_{1}+t_{12} x_{2}+t_{13} x_{3}+t_{14} x_{4}+t_{15} x_{5}+d_{5}^{-}-d_{5}^{+}=\beta_{5} \\
t_{21} x_{1}+t_{22} x_{2}+t_{23} x_{3}+t_{24} x_{4}+t_{25} x_{5}+d_{6}^{-}-d_{6}^{+}=\beta_{6}
\end{gathered}
$$

\section{Appendix B}

\section{Achievement Function:}

Minimize $\mathrm{Z}=P_{1} d_{1}^{-}+P_{2}\left(d_{21}^{-}+d_{22}^{-}+d_{23}^{-}+d_{24}^{-}+d_{25}^{-}\right)$.

$$
+P_{3} d_{3}^{-}+P_{4} d_{4}^{+}+P_{5} d_{5}^{-}+P_{6}\left(d_{6}^{+}+d_{7}^{+}\right)
$$

Subject to,

\section{System Constraints:}

Total budget constraint

$$
\chi_{1} x_{1}+\chi_{2} x_{2}+\chi_{3} x_{3}+\chi_{4} x_{4}+\chi_{5} x_{5} \leq \chi
$$

Allowable time constraints on two machines are

$$
\begin{aligned}
& t_{11} x_{1}+t_{12} x_{2}+t_{13} x_{3}+t_{14} x_{4}+t_{15} x_{5} \leq \beta_{1} \\
& t_{21} x_{1}+t_{22} x_{2}+t_{23} x_{3}+t_{24} x_{4}+t_{25} x_{5} \leq \beta_{2}
\end{aligned}
$$

Inventory space constraint

$$
A_{1} X_{1}+A_{2} X_{2}+A_{3} X_{3}+A_{4} X_{4}+A_{5} X_{5} \leq A
$$

\section{Goal Constraints:}

\section{Priority P1}

Total Production Goal

$$
x_{1}+x_{2}+x_{3}+x_{4}+x_{5}+d_{1}^{-}-d_{1}^{+}=\beta_{3}
$$

\section{Priority P2}

Goal on Production of Different Grades

$$
\begin{aligned}
& x_{1}+d_{21}^{-}-d_{21}^{+}=\delta_{1} \\
& x_{2}+d_{22}^{-}-d_{22}^{+}=\delta_{2} \\
& x_{3}+d_{23}^{-}-d_{23}^{+}=\delta_{3}
\end{aligned}
$$


Priority P3

$$
\begin{aligned}
& x_{4}+d_{24}^{-}-d_{24}^{+}=\delta_{4} \\
& x_{5}+d_{25}^{-}-d_{25}^{+}=\delta_{5}
\end{aligned}
$$

Profit Goal

$$
\alpha_{1} x_{1}+\alpha_{2} x_{2}+\alpha_{3} x_{3}+\alpha_{4} x_{4}+\alpha_{5} x_{5}+d_{3}^{-}-d_{3}^{+}=\alpha
$$

\section{Priority P4}

Production Expenditure Goal

$$
\gamma_{1} x_{1}+\gamma_{2} x_{2}+\gamma_{3} x_{3}+\gamma_{4} x_{4}+\gamma_{5} x_{5}+d_{4}^{-}-d_{4}^{+}=\gamma
$$

$$
\xi_{1}+\xi_{2}+\xi_{3}+\xi_{4}+\xi_{5}+d_{5}^{-}-d_{5}^{+}=\beta_{4}
$$

\section{Priority P6}

Goal on Over Use of Machines

$$
\begin{aligned}
& t_{11} x_{1}+t_{12} x_{2}+t_{13} x_{3}+t_{14} x_{4}+t_{15} x_{5}+d_{6}^{-}-d_{6}^{+}=\beta_{5} \\
& t_{21} x_{1}+t_{22} x_{2}+t_{23} x_{3}+t_{24} x_{4}+t_{25} x_{5}+d_{7}^{-}-d_{7}^{+}=\beta_{6}
\end{aligned}
$$

\begin{tabular}{|c|c|c|c|c|c|c|c|c|}
\hline Type of grades & $\begin{array}{c}\chi_{i} \\
\text { (in Rs.) }\end{array}$ & $\begin{array}{c}t_{1 i} \\
\text { (in Hr.) }\end{array}$ & $\begin{array}{c}t_{2 i} \\
\text { (in Hr.) }\end{array}$ & $\begin{array}{c}A_{i}=25 a_{i} \\
\left(\text { in } \mathrm{m}^{3}\right)\end{array}$ & $\begin{array}{c}\alpha_{i} \\
\text { (in Rs.) }\end{array}$ & $\begin{array}{c}\gamma_{i} \\
\text { (in Rs.) }\end{array}$ & $\begin{array}{c}\xi_{i} \\
\text { (in Kg.) }\end{array}$ & $\begin{array}{c}\delta_{i} \\
\text { (in Kg.) }\end{array}$ \\
\hline Pekoe $\operatorname{dust}\left(X_{1}\right)$ & 118 & .00095 & .0006 & .45 & 28 & 94 & .78 & 500 \\
\hline $\begin{array}{c}\text { Orange } \\
\text { fanning }\left(X_{2}\right)\end{array}$ & 112 & .00085 & .00055 & .65 & 15.4 & 89 & .68 & 20 \\
\hline $\begin{array}{c}\text { Broken } \\
\text { pekoe }\left(X_{3}\right)\end{array}$ & 106 & .0008 & .0005 & .63 & 12 & 76 & .85 & 290 \\
\hline $\operatorname{BOP}($ small $)\left(X_{4}\right)$ & 100 & .00076 & .00048 & .74 & 19 & 68 & .82 & 100 \\
\hline $\operatorname{BOP}\left(X_{5}\right)$ & 98 & .00072 & .00045 & .86 & 24 & 64 & .94 & 850 \\
\hline
\end{tabular}

Where $x_{i}$ 's $\geq 0$ ' $t_{j i}$ 's $\geq 0$ and $d^{+}$'s $\geq 0, d^{-}$'s $\geq 0$ with the condition $d^{+} \cdot d^{-}=0$

Priority P5

Goal on Total Demand

\section{Appendix C}

Table C.1.

Table C.2.

\begin{tabular}{|c|c|c|c|c|c|c|c|c|c|}
\hline $\begin{array}{c}\chi \\
\text { (in Rs.) }\end{array}$ & $\begin{array}{c}\beta_{1} \\
\text { (in Hr.) }\end{array}$ & $\begin{array}{c}\beta_{2} \\
\text { (in Hr.) }\end{array}$ & $\begin{array}{c}\beta_{3} \\
\text { (in Kg.) }\end{array}$ & $\begin{array}{c}\beta_{4} \\
\text { (in Kg.) }\end{array}$ & $\begin{array}{c}\beta_{5} \\
\text { (in Hr.) }\end{array}$ & $\begin{array}{c}\beta_{6} \\
\text { (in Hr.) }\end{array}$ & $\begin{array}{c}A \\
\text { (in m3) }\end{array}$ & $\begin{array}{c}\alpha \\
\text { (in Rs.) }\end{array}$ & $\begin{array}{c}\gamma \\
\text { (in Rs.) }\end{array}$ \\
\hline 230000 & 130 & 125 & 2168 & 1890 & 30 & 25 & 1500 & 55000 & 173000 \\
\hline
\end{tabular}




\section{REFERENCES}

[1] P. Cobb , D.M. Warner, Task substitution among skill classes of nursing personnel, Nursing Res.22(1973)130-137.

[2] V.M. Trivedi, A mixed integer goal programming model for nursing service budgeting, Operat.Res.29(1981)1019-1034.

[3] M.E.Nja, G.A. Udofia, Formulation of the mixed integer goal programming model for flour producing companies, Asian Journal of Mathematics and Statistics.2(3) (2009)55-64.

[4] N.Vivekanandan, K.Viswanathan, Sanjeev Gupta, Optimization of cropping pattern using goal programming approach,OPSEARCH.46(3)(2009)259-274.

[5] J.K. Shim, J.Siegel, Sensitivity analy sis of goal programming with preemption, Int.J.Syst.Sci.11(1980)393-401.

[6] R.K Pati,P Vrat,P Kumar, A goal programming model for paper recy cling system, Omega 36 (2008) 405 - 417.

[7] B.Sinha, N.Sen, Goal Programming approach to tea Industry of Barak Valley of Assam, Applied Mathematical Sciences5 (29)(2011)1409-1419.

[8] N.Mansour,A Rebai,B.Aouni, Prortfolio selection through imprecise goal programming model: Integration of the

[9] M Mezghani,T Loukil, A goal programming model for aggregate production planning problem,Int $\mathrm{J}$ of operational research 4(1)(2009)23-34.

[10] H El-Shishiny, A goal programming model for planning the development of newly reclaimed lands, Agricultural System 26(1988) 245-261.

[11] D K Sharma,D Gosh, D M Mattison, An application of goal programming with penalty functions to transshipment problems, Int $\mathrm{J}$ of Logistics:Research and applications 6(3)(2003)125-136.

[12] A Gupta,G W Evan,A goal programming model for the operation of closed-loop supply chains,Engineering optimization 41(8)(2009)713-735.

[13] F Jolai,M Aghdaghi,A goal programming model for single vehicle routing problem with multiple routes, journal of industrial and system engineering 2(2)154-163.

[14] N K Kwak, C Lee,A linear goal programming model for human resource allocation in health-care organization, Journal of Medical system 21(3)(1997) 129-140.

[15] J.A Alade ,D K Sharma, J K Sharma, A Multi-objective model for planning the exports of developing countries,African Economics and Business Review 1(2)(1998)23-41. 